\title{
Radionuclides Transport from the Hypothetical Disposal Facility in the KURT Field Condition on the Time Domain
}

\section{KURT 부지 환경에 위치한 가상의 처분 시설에서 누출되는 방사성 핵종의 이동을 Time Domain에서 해석하는 방법에 관한 연구}

\author{
Youngtaek Hwang ${ }^{1}$, Nak-Youl Ko ${ }^{2}$, Jong Won Choi ${ }^{2}$ and Seong-Seock Jo ${ }^{1 *}$ \\ ${ }^{1}$ Chung-nam National University, 99 Daehak-ro, Yuseong-gu, Daejeon, Korea \\ ${ }^{2}$ Korea Atomic Energy Research Institute, Daedeok-daero 989-111, Yuseong-gu, Daejeon, Korea \\ 황영택 ${ }^{1}$, 고낙열 ${ }^{2}$, 최종원 ${ }^{2}$, 조성석 $1 *$ \\ 1 충남대학교 녹색에너지기술전문대학원, 대전시 유성구 대학로 99 \\ 2 한국원자력연구원, 대전시 유성구 대덕대로 989 번길 111
}

(Received August 02, 2012 / Revised August 28, 2012 / Approved September 27, 2012)

Based on the data observed and analyzed on a groundwater flow system in the KURT (KAERI Underground Research Tunnel) site, the transport of radionuclides, which were assumed to be released at the supposed position, was calculated on the time-domain. A groundwater pathway from the release position to the surface was identified by simulating the groundwater flow model with the hydrogeological characteristics measured from the field tests in the KURT site. The elapsed time when the radionuclides moved through the pathway is evaluated using TDRW (Time Domain Random Walk) method for simulating the transport on the time-domain. Some retention mechanisms, such as radioactive decay, equilibrium sorption, and matrix diffusion, as well as the advectiondispersion were selected as the factors to influence on the elapsed time. From the simulation results, the effects of the sorption and matrix diffusion, determined by the properties of the radionuclides and underground media, on the transport of the radionuclides were analyzed and a decay chain of the radionuclides was also examined. The radionuclide ratio of the mass discharge into the surface environment to the mass released from the supposed repository did not exceed $10^{-3}$, and it decreased when the matrix diffusion were considered. The method used in this study could be used in preparing the data on radionuclide transport for a safety assessment of a geological disposal facility because the method could evaluate the travel time of the radionuclides considering the transport retention mechanism.

Key words: Particle tracking simulation, Groundwater pathway, Radionuclide transport, Time domain random walk

한국원자력연구원의 지하처분연구시설인 KURT 주변의 지하수 유동 환경과 관련하여 수집 및 분석된 자료를 바탕으로, 가 상의 처분장에서 누출된 방사성 핵종의 이동 현상을 시간 영역(time domain)에서 계산하였다. KURT에서 실시된 현장 시험에 서 밝혀진 수리지질학적 특성을 바탕으로 지하수 유동 모의를 실시하였고, 그 결과를 통해 파악된 지하수 유동 경로를 따라 방 사성 핵종이 이동하는데 걸리는 시간은 시간 영역에서 용질 이동 모의를 하는 TDRW(Time Domain Random Walk) 방식을 통 해 평가하였다. 이류(advection)와 분산(dispersion) 현상 외에 방사성 핵종의 붕괴(decay), 평형 흡착(equilibrium sorption), 암반 기질로의 확산(matrix diffusion) 현상이 용질의 이동 시간에 영향을 주는 것으로 설정되었다. 모의 결과를 통해 방사성 핵종과 지하 매질의 특성에 의한 흡착 현상, 기질 확산 현상이 핵종 이동에 미치는 영향이 분석되었으며, 방사성 핵종의 연쇄 
반응에 의한 영향도 평가하였다. KURT 부지 환경에서 지표로 유출될 수 있다고 계산된 방사성 핵종의 유출량은 처분장에서 누출될 수 있는 양의 $10^{-3}$ 배 미만이었고, 암반 기질로의 확산 및 흡착이 고려되면 그 비율이 더욱 낮아졌다. 본 연구에서 사용 된 핵종 이동 모의 방법은 방사성붕괴나 흡착, 확산 등 이동 지연 현상을 고려하면서 핵종의 이동 시간을 계산할 수 있어 안전 성 평가에서 요구되는 심부 지하에서의 방사성 핵종 이동 관련 자료를 작성하는데 활용될 수 있을 것이다.

중심단어: 입자 추적 모의, 지하수 유동 경로, 방사성 핵종의 이동, 시간 차원 랜덤 워크

*Corresponding Author .E-mail: sscho@cnu.ac.kr, Tel: +82.42.821.5636

\section{1.서 론}

원자력 발전에 의해 생성되는 사용후핵연료를 포함한 고 준위 방사성폐기물을 처분하는 방식 중, 현재 우리나라에 서는 결정질 암반의 지하 심부에 처분 시설을 건설하여 처 분하는 심지층 처분 방식이 연구되고 있다. 처분장 건설 후, 방사성폐기물을 처분 시설로 옮기는 운영 기간이 종료되면 시설을 폐쇄하고 주변 지하 환경을 처분 시설 건설 전으로 되돌려놓게 된다. 이로 인해 처분 시설과 처분 용기가 지하 수와 접촉하게 되고, 처분 용기의 부식이 진행 된다. 처분 용 기가 모두 부식되거나 부식된 틈으로 지하수가 유입되면 고 준위폐기물에 있는 방사성 핵종이 지하수에 용해되어 누출 되기 시작하고, 누출된 핵종은 완충재와 뒷채움재 등의 공 학적 방벽을 거쳐 결정질 암반으로 되어 있는 천연 방벽을 지나 최종적으로 생태계로 유출된다.

처분장 안전성평가 과정에서 핵종의 이동 현상을 규명하 기 위해서는 지하수내 핵종의 다양한 수리지질학적 인자들 에 대한 자료가 요구된다. 따라서, 핵종의 이류(advection), 분산(dispersion)과 더불어 흡착(sorption)과 같이 이동을 지연시키는 기작(mechanism)에 관한 특성들이 처분 시설 이 들어설 부지의 수리지질학적 특성화(characterization) 를 통해 측정되어 처분 시설에서 생태계로 유출되는 핵종 의 양과 이동 거리 및 시간에 관한 자료를 계산하는데 이 용된다.

방사성 핵종의 이동에 관한 자료 중, 이동 경로가 정해 진 상황에서 주어진 경로를 통과하는데 걸리는 시간이 안 전성 평가에 중요한 입력 및 평가 자료로 활용되었고, 통 과 시간을 계산하는데 관심을 두는 연구가 이루어져 왔다 [1,2]. 그리고 그러한 연구들 중에서 핵종의 이동 시간을 공간 영역이 아닌 시간 영역에서 계산하려는 연구도 수행 되었다[3-5]. Banton 등[3]은 공간 영역에서 지하수 내 용 질의 이동을 Lagrangian 방식으로 계산하는데 이용되는 Random Walk 방법을 시간 영역으로 변환하여 계산하
는 TDRW(Time Domain Random Walk) 방법으로 변환 하는 과정을 소개하였는데, 유체에서 움직이는 입자의 운 동 상태를 묘사하는 브라운 운동(Brownian motion)에 의 한 입자의 변화를 미분방정식 형태로 나타내는 FokkerPlanck 방정식을 이용하여 공간 영역의 용질이동 방정식 에서 시간 영역의 TDRW 관련 식을 도출하는 방식이었 다. Painter 등[4]은 1 차원의 일정한 거리를 지나는 용질 이 이동하는데 걸리는 경과 시간을 이류와 분산에 의한 체 류 시간(residence time)과 흡착, 암반으로의 확산(matrix diffusion)과 같은 이동 지연 효과에 의한 시간(retention time)으로 나누고, 용질 입자의 총 이동 경과 시간을 각각 따로 구해진 두 시간을 합산하여 구하는 방식을 이용해 방 사성붕괴가 일어나는 단일 핵종과 붕괴사슬(decay chain) 에 포함된 방사성 핵종의 이동 양상을 모의하였다. 다른 연구에서는, 용질의 지연 효과에 주목하여 지하수 유동로 표면에서의 흡착, 암반 기질로의 확산과 기질 내의 흡착, 일차 반응(fisrt-order reaction) 등을 고려한 용질의 이동 지연 모델을 제시하고 그것을 방사성 핵종의 이동 모의에 적용하였다[5].

한국원자력연구원에서는 고준위 방사성 폐기물 처분 영 역에 대한 부지특성조사 기술을 구축하기 위해 1997년부터 현재까지 한국원자력연구원 주변의 결정질 암반 지역을 대 상으로 지질, 수리지질, 지화학 및 지질역학 조사 등을 수 행하였으며, 2006년 KURT(KAERI Underground Research Tunnel)가 준공된 이후 지하 환경에 대한 다양한 부지특성 조사를 수행해 왔다[6-8]. 지금까지의 연구 자료를 바탕으로 KURT 부지에 대한 전반적인 지하수 유동 환경이 분석되었 다[9].

본 논문의 목적은 KURT 부근의 가상의 방사성폐기물 처 분장으로부터 누출된 핵종의 이동 현상을 시간 영역(Time Domain)에서 계산해보고 그 결과를 도시하는 것이다. 계 산에 필요한 지하수 유동과 관련된 자료는 KURT에서 이 전에 수행된 지하수 유동 관련 측정값 및 모의 결과를 이 
용하였다. 자료를 통해 도출된 지하수의 유동 경로를 통해 핵종이 누출 위치에서 지표까지 이동하는데 걸린 시간을 TDRW(Time Domain Random Walk) 방법을 이용하여 계 산, 분석하였다.

\section{2. 연구 지역}

용질 이동 모의에 이용된 지하수 유동 자료는 KURT 지하 의 지하수 유동 자료를 이용하였다. KURT는 고준위방사성 폐기물의 심지층 처분 연구를 위하여 한국원자력연구원 부 지 내에 설치한 지하 연구 시설이며, 주변 지하 환경의 특성 화를 위해 지질학적, 수리지질학적 측정 및 연구가 수년 전 부터 실시되고 있다[6-9]. 본 논문에서는 지하수 유동과 관련 된 사항만을 간략히 언급하도록 하였다.

\subsection{KURT 주변 수리지질학적 특성}

한국원자력연구원의 심지층 처분 연구를 위한 지하 환 경 연구 시설인 KURT 부근은 갑천이 서남쪽에서 북동쪽 으로 흐르며 계룡산으로 이어지는 대전 분지의 서북부에 해당한다(Fig. 1). 분지 지형으로 인해 보덕봉, 금병산, 도덕봉 등이 서북부 지역의 분수령을 이루고 있으며, 수 계는 전형적인 수지상 분포를 보인다. 유성천 등의 소규 모 하천이 북쪽 또는 서쪽으로 흘러가는 금강 본류와 합 류한다[7].

KURT 부근 지질의 광역적 특성은 기존 문헌[11]을 통해 서 파악하였고, 본 연구 결과에 크게 영향을 미칠 수 있는
국지적 지질 특성은 현장에서 측정된 자료를 이용하여 분 석하였다[7,9]. 이 지역은 선캠브리아기의 화강편마암이 주 로 분포하는 경기육괴에 속하며 중생대의 복운모화강암도 관찰된다.

KURT에서 이루어진 지질 조사를 통해 지질 모델이 구축 되었다 $[7,8]$. 이 지질 모델에서는 지표 조사 자료와 시추공 조사 자료를 통해 상부 토양층과 풍화대, 단열대, 기반암으 로 지질을 구분하고, 각각의 수리적 특성을 이용하여 수리 지질 개념모델을 수리토양대, 수리투수대, 수리암반대로 나 누었다. 이렇게 분류된 수리적 특성을 이용하여 지하수 유 동 모델을 작성하였다[9,12].

작성된 지하수 유동 모델을 이용하여 지하수 유동 모의를 실시하였다[10,12]. KURT 주변의 지하수 유동에 대한 경계 조건을 지정하기 위해, 지하수 유동 모의 영역을 광역 모델 에서 먼저 실시하고, 그 결과를 이용하여 국지 규모 모델의 경계조건을 설정하여 KURT 주변의 국지적 지하수 유동 양 상을 모의하였다. 모의 결과를 보면 지하수는 대체로 지형 의 구배를 반영하여 유동하는 것으로 나타났으며, 국지 규 모에서는 단열대가 수위 분포에 영향을 끼치는 것으로 확 인되었다(Fig. 2).

\section{$2.2 \mathrm{KURT}$ 환경을 이용한 가상의 핵종 누출 위치 설정}

한국원자력연구원에서는 지금까지 연구된 처분 시설의 안전성 평가 방법을 시험적으로 적용해 보기 위해 KURT

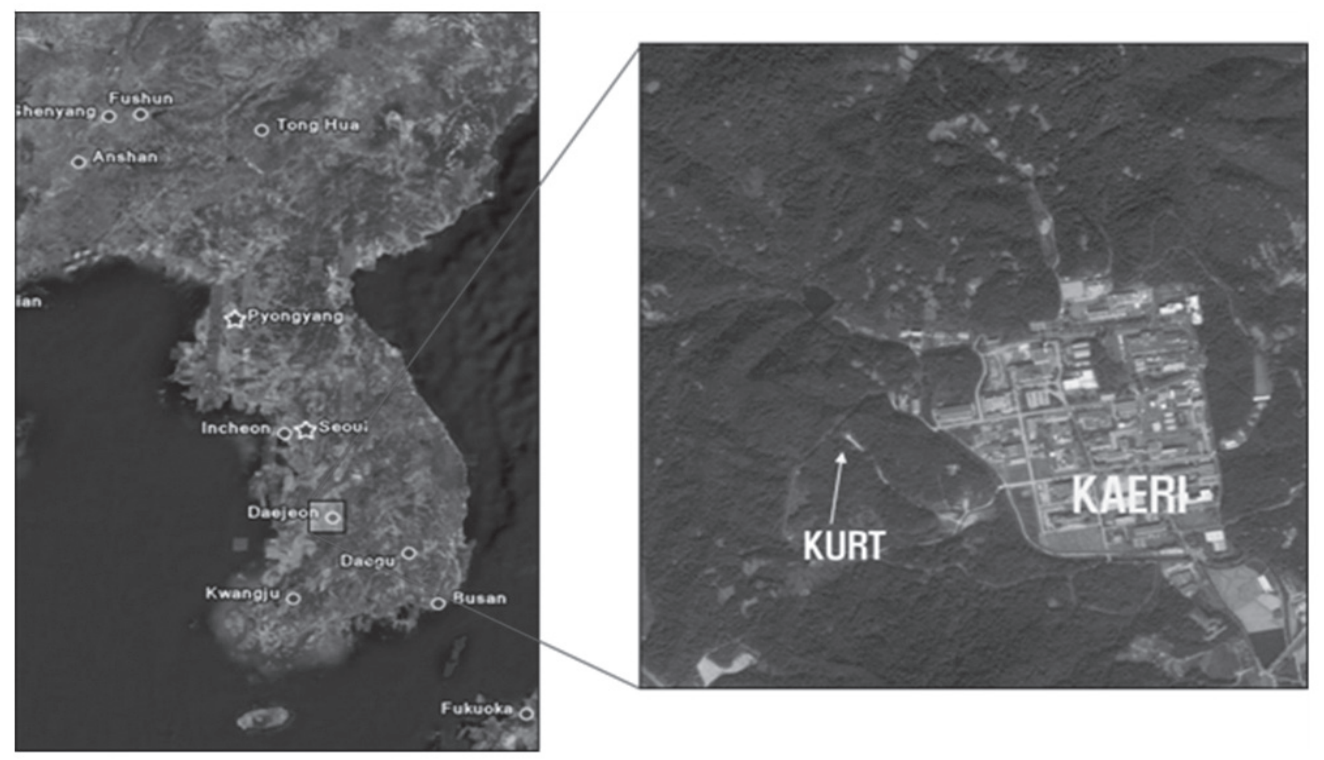

Fig. 1. Location of the KURT [10]. 


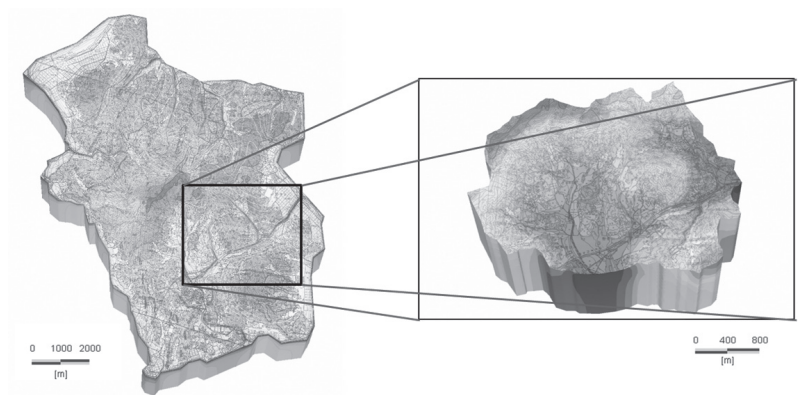

( a )

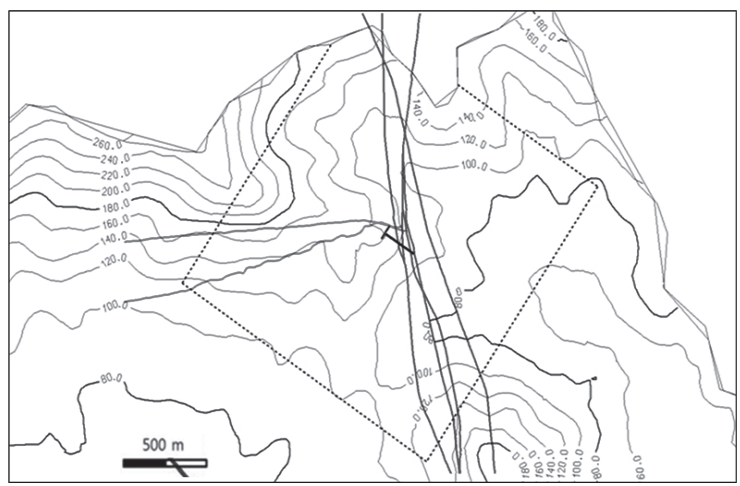

( b )

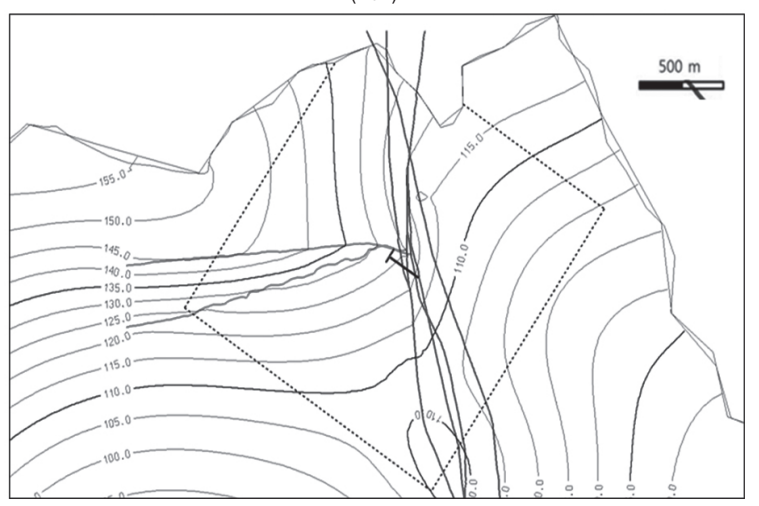

(c)

Fig. 2. Hydraulic head distributions of (a) the regional and local scales, and of (b) the surface and (c) the depth of $-500 \mathrm{~m}$ for the local scale [10].

부지가 포함된 국지 규모의 지하수 유동 모의 결과를 이 용하여 가상의 처분 부지 위치를 선정하고, 그 위치에서 의 입자 추적 모의를 실시하였다[12]. 단열대와의 거리 등 의 제한 조건을 이용하여 심도 $-500 \mathrm{~m}$ 에 처분 위치를 선정 하고, 처분 시설에서 누출되었다고 가정된 핵종이 단열 암 반과 투수성이 큰 단열을 통과하여 지표로 유출되는 상황 에 대한 안전성 평가를 수행하기 위해 Fig. 3의 "R"의 위치 를 대표 지점으로 설정하였다. "R" 위치에서 입자 추적 모 의를 수행하여 지하수가 지표까지 흐르는 유동 경로를 계 산한 결과, Fig. 3과 같이 나타났다[12]. 계산된 유동 경로 는 누출된다고 가정되는 방사성 핵종의 이동을 계산하는 데 이용되었다.

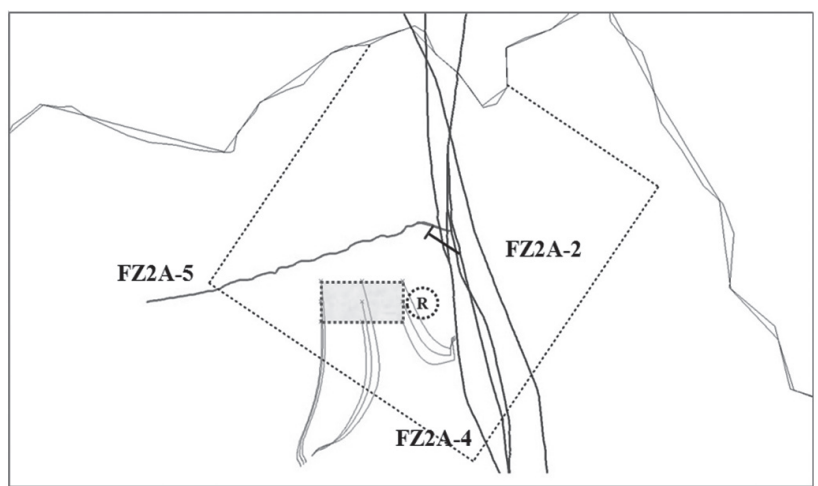

Fig. 3. Results of particle tracking simulations for releases from the hypothetical repository (represented as the small rectangle filled with red color) and a representative position (" $\mathrm{N}$ ") [10].

\section{3. 용질 이동 모의 방법}

\subsection{TDRW 모의 방법}

공간 영역을 계산하는 지하수내 용질 이동 모의 방법이 특 정 시각에서 용질의 농도나 양에 대한 공간적 분포를 계산 하는 것에 유리한데 반해, TDRW 방법은 지정된 공간 또는 배출 지점에서의 용질 이동량에 대한 시간적 변화를 시간 영역에서 계산하는데 유리하다[3-5].

TDRW 방법에서는 입자의 임의적인 운동(Brown motion)을 확률밀도함수를 통해 나타내는 Fokker-Planck식 을 이용하여 시간 영역에서 1 차원의 이류-분산 방정식을 풀어낸다[3]. 1차원적인 유동 경로를 따라 흐르는 지하수에 의한 이류현상과 흐름 방향으로의 분산(longitudinal dispersion) 현상에 의해 계산되는 지하수내 용질의 이동 시 간을 $\tau$ 라고 하면, 용질이 순간적으로 이동 경로의 입구에 서 주입될 때(instantaneous injection) 출구로 나오는 용질 의 양을 표준화(normalization)한 이력곡선(breakthrough curve)은 $\tau$ 에 대한 확률밀도함수가 된다[4]. 그 때, 이 확 률밀도함수의 누적 분포 $\mathrm{F}(\tau)$ 는 다음과 같이 표현된다[1314].

$$
F(\tau)=\frac{1}{2}\left[\operatorname{erfc}\left(\frac{\sqrt{\eta}}{2} \frac{1-\tau^{\prime}}{\sqrt{\tau^{\prime}}}\right)+\exp (\eta) \operatorname{erfc}\left(\frac{\sqrt{\eta}}{2} \frac{1+\tau^{\prime}}{\sqrt{\tau^{\prime}}}\right)\right]
$$

단, $\tau^{\prime}$ 은, $\tau / \bar{\tau}, \bar{\tau}$ 는 이동 경로를 이류만으로 움직일 때의 경과 시간으로 지하수의 유동 시간과 동일하고, $\eta$ 는 $\mathrm{L} / a, \mathrm{~L}$ 은 이동 경로의 길이, $a$ 는 이동 방향으로의 분산도 (dispersivity)를 나타낸다. 
이류와 분산 이외에 지하수내 용질이 이동할 때 발생하는 용질의 이동 지연 현상도 시간 영역에서 계산하였다. 용질 의 이동 경로와 암반간의 경계면에서 발생하는 평형 흡착 (equilibrium sorption)만을 고려하는 경우, 흡착에 의한 이 동 지연 시간 $\mathrm{t}_{\mathrm{ret}}$ 는 다음과 같이 계산된다[4].

$$
t_{\text {ret }}=K_{d} \rho_{b} \tau
$$

이 때, $K_{d}$ 는 분배계수(distribution coefficient), $\rho_{b}$ 는 주어 진 기질의 단위 부피당 고체 입자의 질량(bulk density)이다. 지하수 유동 및 용질의 이동 방향에 수직 방향으로 발생하 는 암반 기질로의 확산(matrix diffusion)과 흡착을 고려하 는 경우에는, 용질의 지연된 이동 시간의 누적 분포는 용질 의 지연 기작에 따라 식 (1)과 유사한 방식으로 다음과 같이 표현된다[15].

$$
F\left(t_{r e t} ; \kappa, \beta\right)=\operatorname{erfc}\left(\frac{\kappa \beta}{2 \sqrt{t_{r e t}}}\right)
$$

이 때, $\int_{0}^{\tau} \frac{1}{b(\vartheta)} d \vartheta, \kappa=n_{m} \sqrt{D^{*} R_{i m}}$ 이며, $b$ 는 용질 이 동 경로의 간극(aperture) 크기의 절반, $\mathrm{n}_{\mathrm{m}}$ 은 기질(matrix)의 공극률, $\mathrm{D} *$ 는 기질로의 확산 계수(matrix diffusion coefficient), $\mathrm{R}_{\mathrm{im}}$ 은 기질에서의 지연 계수(retardation factor)이다.

주어진 경로를 이동하는 지하수내 입자의 경로 통과 시간 은 이류와 분산 현상에 의해 경과된 시간과 흡착 및 확산 등 의 지연 효과에 의해 경과되는 시간을 합쳐서 계산하게 된 다. 식 (1)을 통해 이류와 분산에 의한 경과 시간을, 그리고 식 (2) 또는 (3)을 통해 용질 이동의 지연 효과에 의해 경과 된 시간을 계산한다.

\section{$3.2 \mathrm{TDRW}$ 를 이용한 용질의 통과 시간 계산 방법}

방사성 붕괴 후에 B로 변하는 방사성 핵종 $\mathrm{A}$ 의 입자(particle) 하나가 이동 경로를 통과하는데 걸리는 시간을 계산 하는 과정은 다음과 같다 $[4,5]$.

(1) $R_{1} \in[0,1]$ 인 임의의 변수 $R_{1}$ 을 추출하여 식 (1)에서 $F\left(\tau^{*}\right)=R_{1}$ 을 만족하는 $\tau^{*}$ 를 구한다.

(2) 분산에 의한 영향을 반영하기 위해 $\beta^{*}=\left(\tau^{*} / \bar{\tau}\right) \bar{\beta}$ 를 계산한다. 이 때, $\bar{\beta}$ 는 이류 현상만 있을 경우, 즉 주어
진 경로의 통과 시간이 $\bar{\tau}$ 일 때의 이동 저항(transport resistance)이다.

(3) $t_{r e t}$ 를 계산한다. 평형 흡착만 있는 경우에는 $t_{r e t, A}$ $=K_{d, A} \rho_{b} \tau^{*}$ 와, $t_{r e t, B}=K_{d, B} \rho_{b} \tau^{*}$ 기질로의 확산 및 흡착을 고려하는 경우에는 $R_{2} \in[0,1]$ 인 임의의 변수 $R_{2}$ 를 추출하여 핵종 $\mathrm{A}$ 와 $\mathrm{B}$ 각각에 대해 식 (3)을 이용 해 $F^{-1}\left(R_{2} ; \kappa_{A}, \beta\right), F^{-1}\left(R_{2} ; \kappa_{B}, \beta\right)$ 를 계산한다.

(4) 1 과 3 에서 계산된 시간을 통해 주어진 이동 경로를 방 사성 핵종 $\mathrm{A}$ 와 $\mathrm{B}$ 가 통과하는데 걸리는 시간 $\left(\mathrm{t}_{\mathrm{A}}, \mathrm{t}_{\mathrm{B}}\right)$ 을 계산한다. $t_{A}=\tau^{*}+t_{r e t, A}, t_{B}=\tau^{*}+t_{r e t, B}$ 가 된다.

(5) $R_{3} \in[0,1]$ 인 임의의 변수 $R_{3}$ 을 추출하여 방 사성 붕괴 로 인한 영향을 반영한다. 붕괴 시간 $t_{d}=-(\ln R) / \lambda$ 로 계산된다. 이 때, $\lambda$ 는 붕괴 상 수(decay constant)이다.

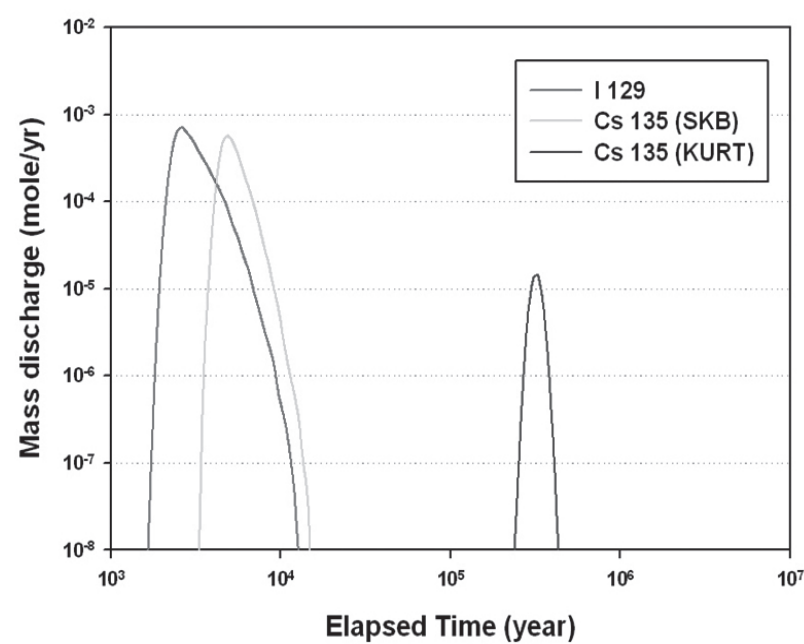

Fig. 4. Results of the transport for ${ }^{129} \mathrm{I}$ and ${ }^{135} \mathrm{Cs}$ using the data from SKB and KURT site under the equilibrium sorption model.

Table 1. Values of decay constant $(\lambda)$ and distribution coefficient $\left(K_{d}\right)$ used in this study.

\begin{tabular}{lccc}
\hline \multirow{2}{*}{ Nuclide } & $\begin{array}{c}\text { Decay constant, } \\
\lambda(\mathrm{yr}-1)\end{array}$ & \multicolumn{2}{c}{ Distribution coefficient, $K_{d}\left(\mathrm{~m}^{3} / \mathrm{kg}\right)$} \\
\cline { 3 - 4 } & $4.415 \times 10^{-8}$ & KURT [10] & SKB $[18]$ \\
\hline${ }^{129} \mathrm{I}$ & 0.0 & 0.0 \\
\hline${ }^{135} \mathrm{Cs}$ & $3.014 \times 10^{-7}$ & $5.2 \times 10^{-2}$ & $3.5 \times 10^{-4}$ \\
\hline${ }^{241} \mathrm{Am}$ & $1.605 \times 10^{-3}$ & $1.0 \times 10^{1}$ & $1.5 \times 10^{-2}$ \\
\hline${ }^{237} \mathrm{~Np}$ & $3.239 \times 10^{-7}$ & $1.7 \times 10^{-1}$ & $5.3 \times 10^{-2}$ \\
\hline${ }^{233} \mathrm{U}$ & $4.387 \times 10^{-6}$ & $4.3 \times 10^{-2}$ & $5.3 \times 10^{-2}$ \\
\hline${ }^{229} \mathrm{Th}$ & $9.445 \times 10^{-5}$ & $5.0 \times 10^{0}$ & $5.3 \times 10^{-2}$ \\
\hline
\end{tabular}


(6) $t_{A}<t_{d}$ 이면, 주어진 이동 경로에서는 방사성붕괴가 일어나지 않게 되므로 방사성 핵종 A는 붕괴되지 않고 주어진 경로의 유출 지점에 도착한다.

(7) $t_{A} \geq t_{d}$ 이면 방사성 붕괴로 인해 입자가 $\mathrm{A}$ 에서 $\mathrm{B}$ 로 변하게 된다. $t_{d}$ 가 되기 전까지는 $\mathrm{A}$ 로, 그 이후로는 $\mathrm{B}$ 로 이동하기 때문에 주어진 경로를 지나는데 걸리는 시간

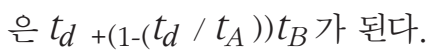

위의 계산 과정을 미리 정해놓은 입자의 수만큼 시행하 면 유입된 방사성 핵종이 주어진 이동 경로를 통과하는 데 걸리는 경과 시간의 누적 분포를 구할 수 있게 된다. 이 경우, 입자 하나가 나타내는 양은 유입된 방사성 핵종 의 전체 양을 입자의 수로 나눈 만큼의 것이 된다. 위에 서 기술한 방식으로 TDRW를 실행하는 프로그램을 통해 지하수를 따라 흐르는 가상의 방사성 핵종의 이동을 모 의하였다[16].

\section{4. 모의 결과}

\subsection{TDRW 모의를 위한 입력값}

지하수 유동 모의를 통해 구성한 지하수의 유동 경로를 이 용하여 TDRW 방법을 적용해 평형 흡착과 암반 기질 확산 및 기질 내 흡착을 반영하는 방사성 핵종 이동 모의를 수행하였 다. 분산도 $(\alpha)$ 는 각 이동 경로 길이의 0.1 배로 하였고[17], 암반 기질의 고체 입자의 밀도 $\left(\rho_{s}\right)$ 는 $2,650 \mathrm{~kg} / \mathrm{m}^{3}$, 공극률 $\left(n_{m}\right)$ 은 0.002 , 간극의 크기 $(b)$ 는 핵종의 이동 구간에 따라 $0.0001 \mathrm{~m}$ 와 $0.002 \mathrm{~m}$ 로, 암반 기질에서의 확산 계수(D*)는

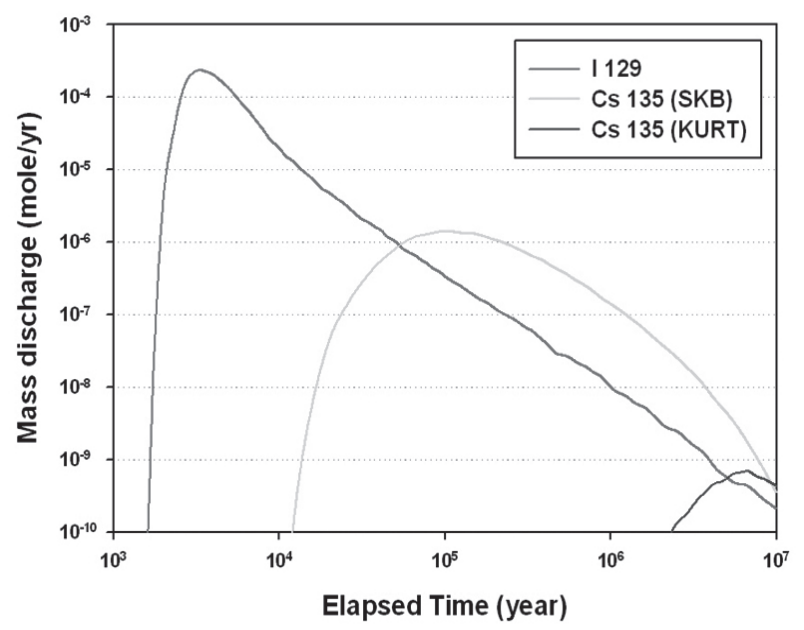

Fig. 5. Results of the transport for ${ }^{129} \mathrm{I}$ and ${ }^{135} \mathrm{C}$ s using the data from SKB and KURT site under the matrix diffusion model.
모든 핵종에 대해 $10^{-6} \mathrm{~m}^{2} / \mathrm{yr}$ 로 설정하였다. 설정된 값들은 KURT의 현장 조사 자료를 주로 이용하였으나, 공극률은 스웨덴의 $\mathrm{SKB}$ 의 자료를 참고하였고, 자료를 구하기 어려 운 수치들은 가정하여 모의에 이용하였다 $[10,11,18]$. 가정 된 공극률 값을 이용해서, 이류만으로 움직이게 되는 지하 수의 유동 시간은 $2.32 \times 10^{3}$ 년이 걸리는 것으로 계산되었 다. 각 핵종에 대한 붕괴 상수(decay constant)와 분배 계 수 $\left(K_{d}\right)$ 는 Table 1 에 정리하였다. 분배 계수의 경우, KURT 기반 연구에서 이용된 수치[10]와 스웨덴의 SKB에서 결정 론적 안전성 평가에 쓰인 수치[18]를 사용하여 그에 따른 차이를 살펴보았다. 방사성 핵종 이동의 지연 기작을 나타 내는 모델로는 지하수 유동 경로와 주변 암반의 표면에서 만 일어나는 흡착만을 고려하는 평형 흡착 모델(equilibrium sorption model)과 암반의 기질 안으로 지하수 유동 방향에 수직 방향의 확산과 기질에서의 흡착을 고려하는

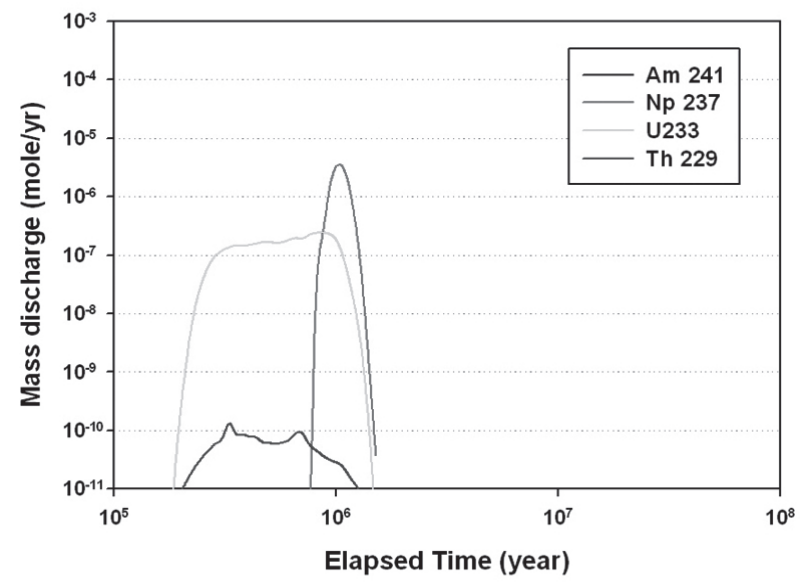

( a )

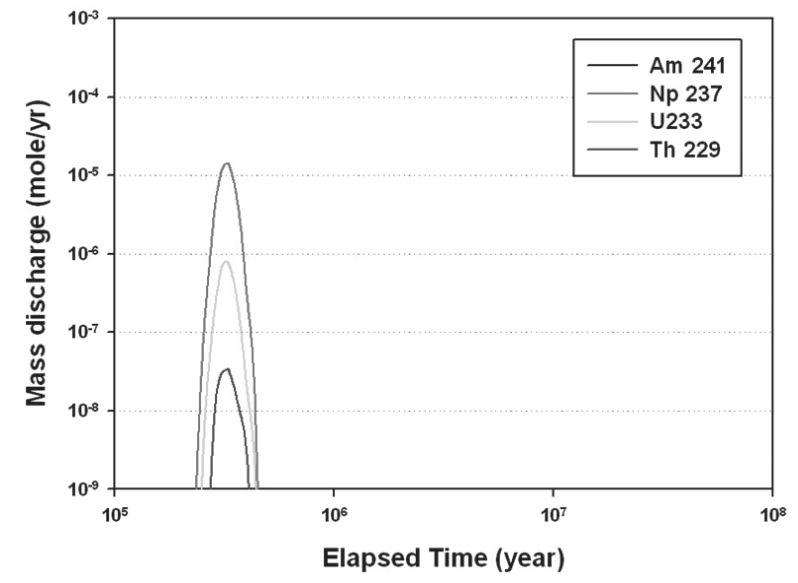

( b )

Fig. 6. Results of the transport of the radionuclides included in a fourmember decay chain with ${ }^{241} \mathrm{Am},{ }^{237} \mathrm{~Np},{ }^{233} \mathrm{U}$ and ${ }^{229} \mathrm{Th}$ using the data from (a) KURT and (b) SKB under the equilibrium sorption model. 


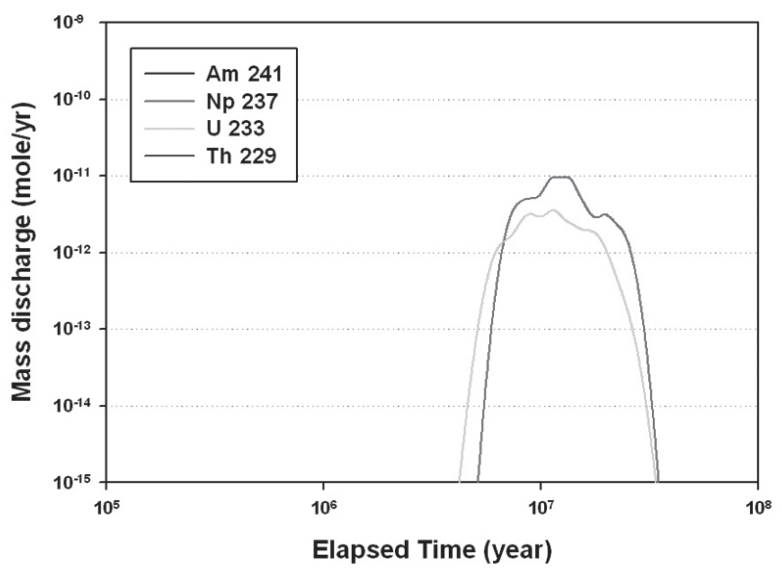

( a )

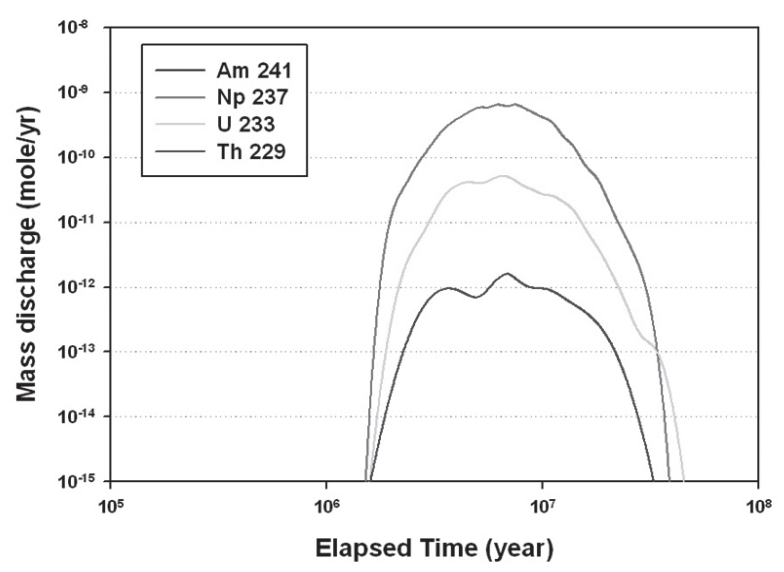

(b)

Fig. 7. Results of the transport of the radionuclides included in a fourmember decay chain with ${ }^{241} \mathrm{Am},{ }^{237} \mathrm{~Np},{ }^{233} \mathrm{U}$ and ${ }^{229} \mathrm{Th}$ using the data from (a) KURT and (b) SKB under the matrix diffusion model.

기질 확산 모델(matrix diffusion model)을 이용하였다.

\section{2 방사성 핵종의 붕괴와 평형 흡착 모의}

일반적인 방사성 핵종의 이동을 모의하기 위해 흡착이 거 의 일어나지 않는 ${ }^{129} \mathrm{I}$ 와 ${ }^{123} \mathrm{Cs}$ 를 이용하여 KURT 환경에서 방사성 붕괴를 일으키는 핵종의 이동을 모의하였다. 붕괴 상수와 분배 계수는 Table 1 의 값을 이용하였다. 핵종 각각 의 초기 시간당 누출량은 $0.001 \mathrm{~mole} / \mathrm{yr}$ 로 하였고, 10,000 년간 누출이 일어나며, 시간이 지남에 따라 $0.001 \mathrm{yr}^{-1}$ 의 비율로 지수함수적으로 시간당 누출량이 감소하여 총 1.0 mole이 누출되는 것으로 가정하였다.

평형 흡착 모델에서의 모의결과를 보면, ${ }^{129} \mathrm{I}$ 는 $\mathrm{KURT}$ 와 SKB 자료 모두에서 같은 이동 양상을 보였다(Fig. 4). 이는 양쪽의 자료 모두에서 ${ }^{129}$ I가 흡착하지 않기 때문인 것으로 보인다. ${ }^{135} \mathrm{Cs}$ 의 경우는 분배 계수의 차이로 인해 $\mathrm{KURT}$ 의
분배 계수 자료를 이용한 경우의 이동 지연 현상이 더 크게 일어나고, 지표로 유출되는 시간당 유출량의 최대값도 SKB 의 흡착 자료에 비해 더 낮게 계산되었다.

기질 확산 모델에서의 모의 결과를 보면, ${ }^{129} \mathrm{I}$ 는 유출되는 시 점은 평형 흡착의 경우와 거의 비슷하지만, 시간당 유출량은 확산의 영향에 의해 앞의 결과에 비해 낮은 최대값을 보이고, 유출되는 기간도 길어지는 tailing 현상이 보인다(Fig. 5). ${ }^{135} \mathrm{Cs}$ 의 경우 기질 내 흡착으로 인해 누출 시간마저 크게 지연되는 현상을 보인다. 또한 KURT 부지의 환경에서는 시간당 유출량 이 $10^{-9} \mathrm{~mole} / \mathrm{yr}$ 를 넘지 않으며, 평형 흡착 환경에 비해 10배 정도 늦은 시간에 유출이 시작되는 것으로 나타났다.

\section{3 방사성 핵종의 연쇄반응 모의}

처분되는 방사성 핵종의 일부는 붕괴사슬(decay chain)에 포함되어 방사성붕괴에 의해 다른 핵종으로 변환하기도 한 다. 따라서 그러한 조건에 대한 이동 모의도 필요하며, 여기 에서는 ${ }^{241} \mathrm{Am} \rightarrow{ }^{237} \mathrm{~Np} \rightarrow{ }^{233} \mathrm{U} \rightarrow{ }^{229} \mathrm{Th}$ 순서의 붕괴사슬을 선택하여 모의하였다. 핵종이 누출되는 위치에서는 ${ }^{241} \mathrm{Am}$ 만이 누출된다고 하고, 초기 시간당 누출량은 $0.001 \mathrm{~mole} /$ $\mathrm{yr}, 10,000$ 년간 누출이 일어나며, 시간이 지남에 따라 0.001 $\mathrm{yr}^{-1}$ 의 비율로 지수함수적으로 ${ }^{241} \mathrm{Am}$ 의 시간당 누출량이 감 소하여 총 1.0 mole이 누출되는 것으로 가정하였다.

평형 흡착 모델에서의 모의결과를 보면, KURT 기반 안전 성 평가와 SKB의 안전성 평가에서 쓰인 각 핵종의 분배 계 수값에 의한 영향이 더 크게 나타난다(Fig. 6). ${ }^{241} \mathrm{Am}$ 은 상 대적으로 매우 짧은 반감기 때문에 두 개의 모의에서 모두 나타나지 않았다. 반감기가 매우 긴 ${ }^{237} \mathrm{~Np}$ 는 두 모의에서 모 두 나타나지만, KURT에서 이용된 분배 계수값이 훨씬 커서 그로 인한 지연 효과에 의해 지표에 더 늦게 유출되는 것으 로 계산되었다(Fig. 6(a)). 또한 KURT 자료에서 ${ }^{233} \mathrm{U}$ 의 분 배 계수가 ${ }^{237} \mathrm{~Np}$ 보다 작아 흡착이 적게 일어나고, 그로 인 한 지연 효과도 더 적게 일어나기 때문에, 방사성붕괴에 의 해 ${ }^{237} \mathrm{~Np}$ 로부터 생성된 ${ }^{233} \mathrm{U}$ 가 ${ }^{237} \mathrm{~Np}$ 보다 앞서 지표에 유출 되는 것으로 나타났다(Fig. 6(a)). ${ }^{233} \mathrm{U}$ 의 시간당 유출량이 어느 정도 일정하게 유지되는 것은 ${ }^{237} \mathrm{~Np}$ 의 방사성 붕괴로 인한 영향으로 보인다. 이에 반해 SKB의 자료에서는 ${ }^{237} \mathrm{~Np}$, ${ }^{233} \mathrm{U},{ }^{229} \mathrm{Th}$ 의 분배 계수가 동일하게 설정되었기 때문에 서 로 비슷한 시각에서 시간당 유출량의 최대값을 보이며, 각 각의 분배 계수가 KURT 자료보다 작기 때문에 지표로의 유 출 시점도 더 빠른 것으로 나타났다(Fig. 6(b)).

기질 확산 모델의 결과에서, KURT의 분배 계수 자료를 이용할 경우 지표로 유출되는 방사성 핵종은 ${ }^{237} \mathrm{~Np}$ 와 ${ }^{233} \mathrm{U}$ 뿐 
이였으며, 시간당 질량 유출량은 $10^{-10} \mathrm{~mole} / \mathrm{yr}$ 이하였다(Fig. 7(a)). 또한 ${ }^{229} \mathrm{Th}$ 은 시간당 유출량이 $10^{-15} \mathrm{~mole} / \mathrm{yr}$ 를 넘지 않 았다. SKB의 자료를 이용한 모의에서는 암반 기질의 영향 에 의해 평형 흡착 모형에 비해 ${ }^{237} \mathrm{~Np}$ 가 유출되는 시각이 약 10 배 정도 지연되고, 그 양도 104 배 이상의 비율로 감 소하였다(Fig. 7(b)). SKB의 분배 계수 자료에서 동일한 값 을 갖는 세 핵종의 시간당 유출량은 비슷한 시각에서 최대 값을 보였다.

\section{5. 결 론}

한국원자력연구원 부지 내에 건설된 KURT 환경을 이용 한 안전성 평가에 이용된 수리지질학적 자료를 이용하여 KURT 기반의 가상의 처분 부지에서 누출되었다고 가정한 방사성 핵종의 이동을 시간 영역에서 계산하는 TDRW 방 법을 이용하여 계산하였다. 계산에 필요한 지하수 유동 경 로에 관한 정보는 KURT 자료를 이용하여 획득하였다. 가상 의 누출 위치에서 방사성 핵종이 누출되었을 때, 이송과 분 산에 의한 이동 이외에 이동 시간을 지연시키는 모델로 평 형 흡착과 암반 기질 확산 모델을 선정하고, 그로 인한 영향 을 평가하였다. 방사성 핵종은 흡착이 거의 일어나지 않는 종류와, 연쇄 반응으로 핵종의 붕괴와 생성이 동시에 일어 나는 종류를 선정하여 모의하였다.

모의에 사용된 TDRW 방법은 일반적으로 알려진 방사성 핵종의 붕괴와 흡착 양상을 잘 표현하는 것으로 나타났다. 흡착의 정도를 표현하는 분배 계수의 차이로 인해 발생하 는 핵종 도달 시각의 지연 효과를 잘 표현하였다. 연쇄 반 응에서는 분배 계수의 차이로 인해 더 늦게 생성되는 핵종 이 더 먼저 생성되는 핵종보다 빨리 유출되는 양상도 보여 주었다. 이는 이 연구에서 이용된 방사성 핵종의 모의 방법 이 지하 환경을 통과하는 방사성 핵종의 이동 양상을 잘 보 여줄 수 있음을 보여준다.

모의 결과를 비교하면, 암반 기질로의 확산을 고려하는 모 델에서 매우 큰 시간 지연 효과가 나타남을 알 수 있다. 이 는 기질로의 확산 외에 기질에서의 흡착 반응에 의한 것으 로 보이며, 유출 시각의 지연으로 인해 방사성 붕괴가 더 많 이 일어나서 핵종이 유출 지점에 다다르기 전에 모두 붕괴 되는 현상도 보여주었다. 이는 암반의 기질이 자연방벽의 역할을 한 것으로 볼 수 있으며, 이용된 모의 방법이 그런 현 상을 잘 나타내 주었다고 할 수 있다. 또한 자연방벽의 역할 을 보다 의미 있게 평가하기 위해서는 각 핵종의 확산 계수 나 분배 계수와 같은 핵종과 암반의 상호 작용에 대한 자료 가 보다 정밀하게 준비되어야 한다는 것을 알려주고 있다.

\section{감사의 글}

이 논문은 교육과학기술부 원자력연구개발사업의 지원을 받았음을 밝히며 이에 감사드립니다.

\section{REFERENCES}

[1] A. F. B. Tompson and L.W. Gelhar, "Numerical Simulation of Solute Transport in Three-Dimensional Randomly Heterogeneous Porous Media," Water Resources Research, 26(10), pp. 2541-2562 (1990).

[2] R. Yamashita and H. Kimura, "Particle Tracking Technique for Nuclide Decay Chain Transport in Fractured Porous Media", Journal of Nuclear Science and Technology, 27(11), pp. 1041-1049 (1990).

[3] O. Banton, F. Delay and G. Porel, "A New Time Domain Random Walk Method for Solute Transport in 1-D Heterogeneous Media", Ground Water, 35(6), pp. 1008-1013 (1997).

[4] S.L. Painter, V. Cvetkovic and O. Pensado, "TimeDomain Random Walk Algorithm for Simulating Radionuclide Transport in Fractured Porous Rock", Nuclear Technology, 163(1), pp. 129-136 (2008a).

[5] S. Painter, V. Cvetkovic, J. Mancillas and O. Pensado, "Time-Domain Particle Tracking Methods for Simulating Transport with Retention and First-Order Transformation", Water Resources Research, 44, W01406, doi:10.1029/2007WR005944 (2008b).

[6] W.-J. Cho, S. Kwon, J.-H. Park and J.-W. Choi, "KAERI Underground Research Tunnel (KURT)", Journal of the Korean Radioactive Waste Society, 5(3), pp. 239-255 (2007).

[7] K.W. Park, Y.K. Koh, K.S. Kim and J.W. Choi, "Construction of the Geological Model around KURT area based on the surface investigations", Journal of the Korean Radioactive Waste Society, 7(4), pp. 191-205 (2009).

[8] K.W. Park, K.S. Kim, Y.K. Koh and J.W. Choi, "Synthetic Study on the Geological and Hydrogeological Model around KURT", Journal of the Korean Radioactive Waste Society, 9(1), pp. 13-21 (2011).

[9] Korea Atomic Energy Research Institute, HLW long- 
term management technology development - Assessment of deep geological environmental condition for HLW disposal in Korea, KAERI Research Report, 435 p., KAERI/RR-3109/2009 (2010).

[10] Korea Atomic Energy Research Institute, Geological disposal of pyroprocessed waste from PWR spent nuclear fuel in Korea, KAERI Technical Report, 192 p., KAERI/TR-4525/2011 (2011).

[11] Korea Atomic Energy Research Institute, HLW long-term management technology development Assessment of deep geological environmental condition, KAERI Research Report, 503 p., KAERI/RR2783/2006 (2007).

[12] K.S. Kim, K.W. Park, G.Y. Kim and H.J. Choi, Development of Advanced Korean Reference HLW Disposal System - Site Characteristics, KAERI Technical Report, 64 p., KAERI/TR-4265/2011 (2011).

[13] A. Kreft and A. Zuber, "On the Physical Meaning of the Dispersion Equation and Its Solution for Different Initial and Boundary Conditions", Chemical Engineering Science, 33(11), pp. 1471-1480 (1978).

[14] A. Ogata and R.B. Banks, A Solution of the Differential Equation of Longitudinal Dispersion in Porous Media, USGS Prof. Paper 411-A, U.S. Geological Survey (1961).

[15] V. Cuetkovic, J.O. Selroos and H. Cheng, "Transport of Reactive Tracers in Rock Fractures", Journal of Fluid Mechanics, 378, pp. 335-356 (1999).

[16] S. Painter and J. Mancillas, User's manual for TDRW version 2.1: radionuclide transport by timedomain random walk, 14 p., (2009)

[17] J.F. Pickens and G.E. Grisak, "Scale-dependent dispersion in a stratified granular aquifer", Water Resources Research, 17(4), pp. 1191-1211 (1981).

[18] SKB, Data report for the safety assessment SRSite, SKB Technical report, pp. 183-391, TR-10-52 (2010). 